Document downloaded from:

http://hdl.handle.net/10251/49178

This paper must be cited as:

Silvestre Martínez, R.; Medel Colmenar, E.; García García, A.; Navas, J. (2013). Utilizing recycled ceramic aggregates obtained from tile industry in the design of open graded wearing course on both laboratory and in situ basis. Materials and Design. 50:471-478. doi:10.1016/j.matdes.2013.03.041.

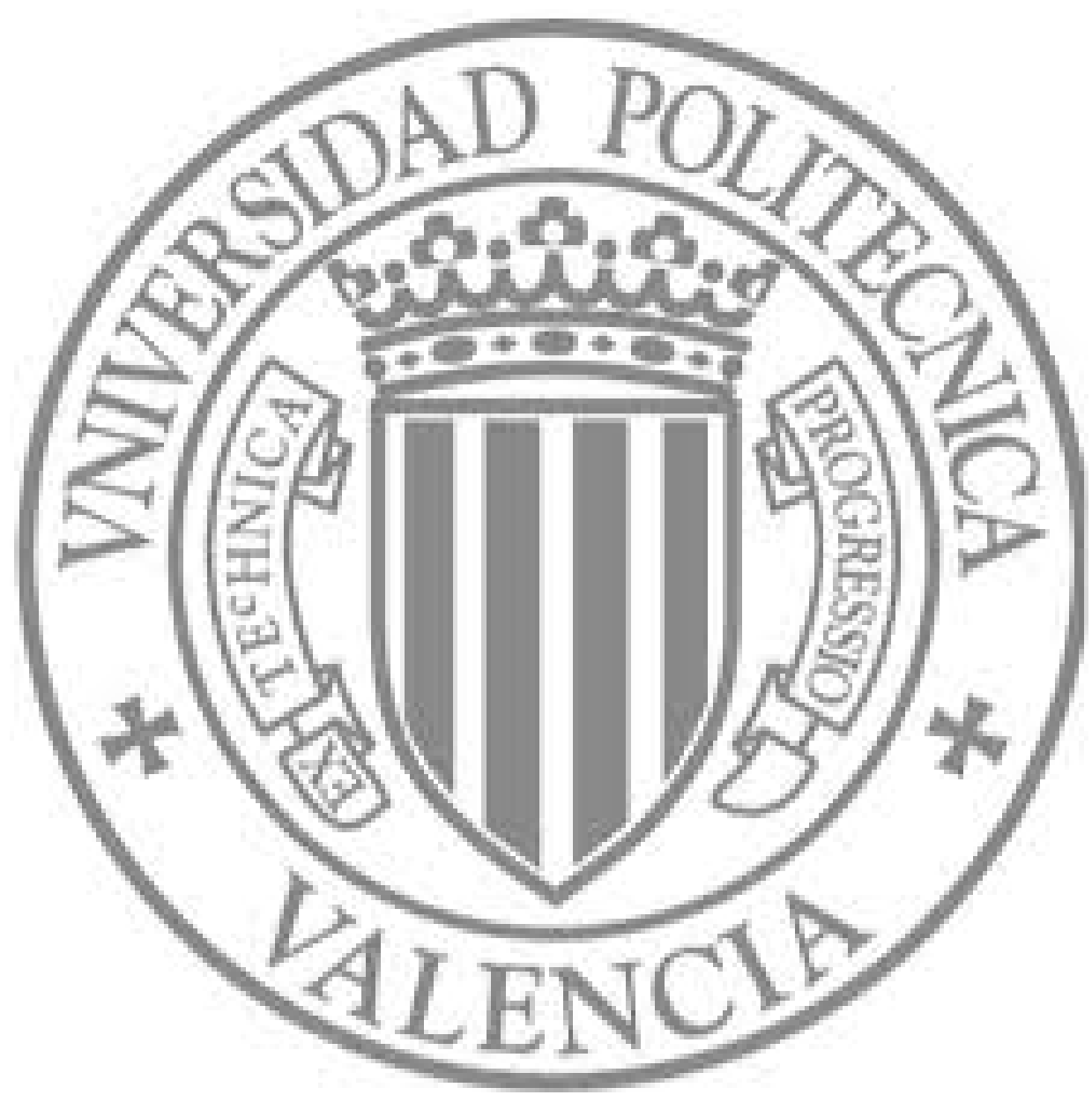

The final publication is available at

http://dx.doi.org/10.1016/j.matdes.2013.03.041

Copyright Elsevier 


\section{Utilizing recycled ceramic aggregates obtained from tile industry in the design of open graded wearing course on both laboratory and in situ basis}

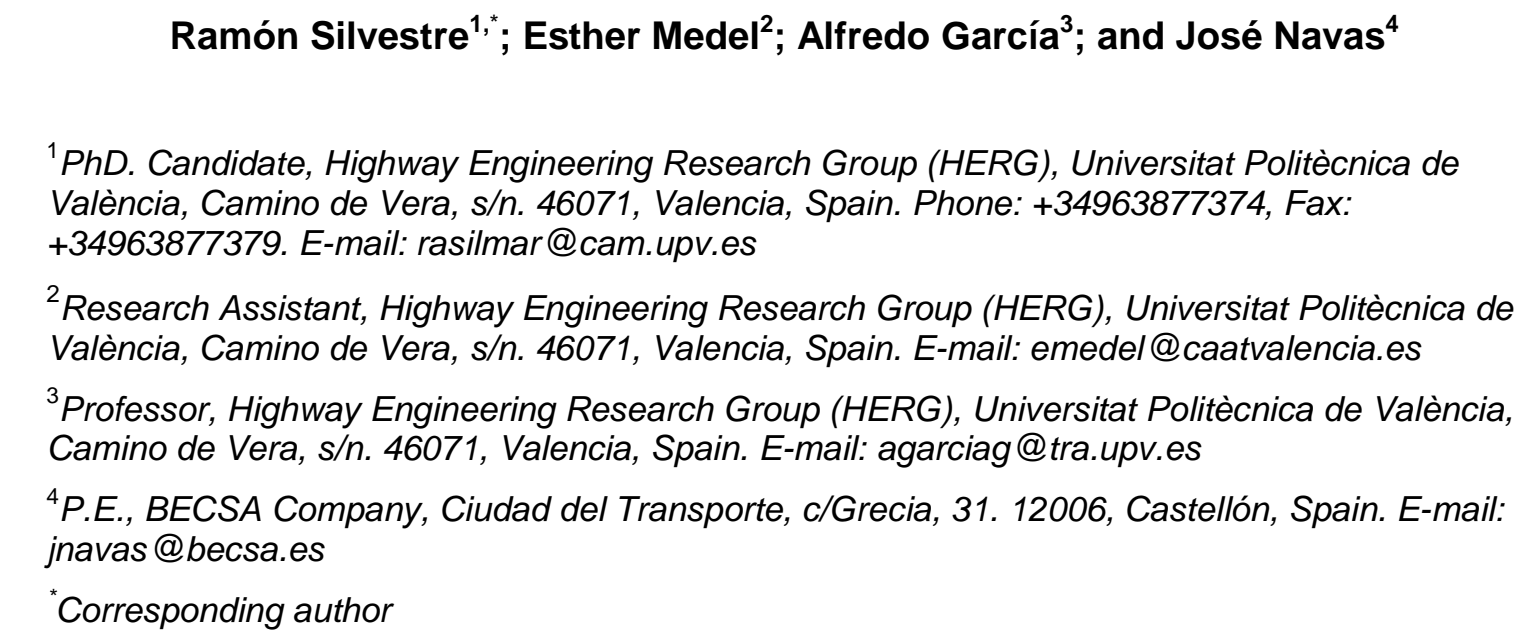

\section{Abstract}

The purpose of the research was to evaluate the technical feasibility of using porcelain and ceramic stoneware tile wastes as aggregate replacement in hot bituminous open graded wearing courses. It is believed that it would reduce the environmental effects of wastes disposal and the natural aggregate demand. The investigated bituminous mix course was an open graded wearing course. Ceramic tile industry wastes were treated to obtain recycled aggregates. These aggregates were characterized and tested to see their suitability to be utilised in bituminous mixtures. The design process of mixture consisted on the study of mixtures prepared with natural and recycled aggregates. The mixtures were produced in both the laboratory and an asphalt plant basis, evaluating the influence of in situ production and scale factors. Recycled ceramic aggregates content was established to obtain appropriate mechanical and superficial characteristics, besides maximizing re-utilization of recycled materials. Up to $30 \%$ of recycled ceramic aggregates content by aggregates weight was found to be adequate. However, the partial substitution of natural aggregate by recycled ceramic aggregates involved higher water sensitivity in the mixture. The open graded wearing course with recycled ceramic aggregates was considered to be suitable for medium to low traffic volume roads, though further research is deemed to be necessary for technical and economical viability.

Keywords: Asphalt pavement, recycled aggregate; stoneware waste; porcelain waste; open graded wearing course; very thin surface course 
Excess stocks and defective products generate a large volume of waste outputs in the ceramic tile industry. Specifically, the Tiles and Pavements Spanish Producers Association estimated 85,000 tons of ceramic waste outputs to landfill in the Valencian Region (Spain) for 2007. Chemical and mechanical characteristics of ceramic tile wastes could allow their use as raw material for recycled aggregates production. The reutilization of these wastes would result in a reduction of environmental impacts and waste management costs. Particularly, the integration of recycled ceramic aggregates as a partial substitute of natural aggregates for road construction and maintenance would reduce natural quarried aggregate demand, besides waste landfill pressures.

The use of recycled materials as aggregates for road construction has been widely investigated: filled embankment [1]; mortar and concrete utilisation [2]; lower, base or sub-base granular courses [3]; or, integrated in hot-mix asphalt (HMA), either in the form of gravel, sand or filler [4] [5] [6] [7].

Regarding recycled aggregates utilization in bituminous mixtures for road construction or maintenance, several suitable materials were established as possible raw materials [8] [9]: slag from iron and steel blast furnace; china clay and sand; fly ash from coal fuel ash powder; foundry sand; sintered household waste; reclaimed asphalt pavement; recycled concrete; recycled glass; plastic waste; and crushed ceramics. Each recycled aggregate has specific problems and determines HMA properties.

In Spain, the General Technical Specifications for Road and Bridge Works (PG-3) [10] allows the use of artificial aggregates in HMA, which meet the required specifications. In particular, recycled aggregate utilisation from the ceramic industry wastes was largely considered in road construction as: landfills; sub-base courses on low-volume roads; concrete blocks; and, manufacture of concrete [11] [12] [13]. Nonetheless, the research on using ceramic wastes in asphalt concrete is scarce. Most of them were dedicated to the use of ceramic materials from different industries as filler in HMA [12]. Muniandy [14] indicated the improved stiffness and the potential rutting resistance of Stone 
conventional limestone filler. Gahlot [15] point to the feasibility of adding up to $15 \%$ of recycled ceramic filler by total aggregates weight-from ceramic electrical insulators crushing-in HMA showing no significant differences respect to conventional aggregate mixture.

The research on using bigger ceramic particles in hot bituminous mixtures has been far less. In this field, Krüger and Solas [16] investigated the use of sanitary ceramic wastes as recycled aggregates for road surface courses. High whiteness and hardness of recycled aggregates from sanitary ceramic wastes improved sunlight reflection, avoiding heating during summer months and increased pavement stability, further improving the visual contrast in the roadway.

Van de Ven et al. [9] studied the feasibility of adding crushed ceramic waste aggregate-from electrical insulators-in a base course mixture regarding mechanical properties, but also leaching behavior. He replaced $15 \%$ of the coarse aggregates by ceramic waste aggregate in a base course resulting in good mechanical and leaching properties of the mixture. No water sensitivity was detected, but decreasing Marshall stability was $13 \%$ and many smooth ceramic pieces detached from the samples. This showed a lack of asphalt-ceramic adhesion.

Feng et al. [4] evaluated the performance and thermal conductivity in asphalt pavements with different percentages of crushed ceramic waste from sanitary industry. The reference wearing mixture-SAC-10- was designed with basalt aggregate and filler made of calcium carbonate, 80/100-penetration grade base asphalt and SBS (styrene-butadiene-styrene) modified asphalt. Only $4.75 \mathrm{~mm}$ and $9.5 \mathrm{~mm}$ size scraps from crushed ceramic waste were collected as recycled coarse aggregate. The recycled aggregates usually presented ceramic glaze on the surface, preventing entire asphalt-aggregate adherence. The addition of lower percentage of recycled aggregate reduced the thermal conductivity and rutting potential. Nonetheless, higher content could increase thermal accumulation and cause poor resistance, premature distress and rutting damage. They concluded that asphalt mixtures with up to $40 \%$ substitution of natural aggregate by recycled aggregate could satisfy the wearing performance requirements in pavements.

\section{Objective and scope}

Based on the findings of previous studies regarding ceramic waste aggregates, the main aim of the research is to explore the feasibility of Utilizing stoneware and porcelain waste from the ceramic tile industry as a potential raw material in asphalt mixtures. This paper investigates specifically the treatment of this waste to obtain a recycled ceramic aggregate $(R C A)$ and its 
96

97

98

application as a partial substitute for natural coarse aggregates in open graded wearing courses-also called very thin surface courses. The Marshall Method [17] is employed for the mixture design as well as European CE marking standards [18]. The performance evaluation for the asphalt mixtures are carried out in both laboratory and asphalt plant basis applying Marshall and European standard tests. It is expected that the obtained results allow the evaluation of the potential viability of using RCAs into asphalt concrete mixtures for open graded wearing courses in function of traffic volume. Nonetheless, further research of experimental sections under real traffic conditions will be necessary for the future validation.

\section{Materials}

\subsection{Ceramic waste and aggregates}

The ceramic tile industry wastes were stoneware and porcelain stoneware tiles from landfills. Those materials are characterized by their high bending strength and abrasion resistance, as well as low water absorption. Besides, some tiles presented glazed surface. Stoneware (Figure 1.a) and porcelain stoneware (Figure 1.b) wastes from tile industry were used as raw materials to produce recycled ceramic aggregates (RCA).

These wastes were treated to reduce their dimension and to adjust to the required particle size. The treatment consisted on: selection and collection; bulldozer trampling; mechanical double trommel screening; crushing and grading in treatment plant. The resulted particle sizes of recycled ceramic aggregates were: 0-4 $\mathrm{mm}$ fine fraction (Figure 1.c); and, 4-11 mm coarse fraction (Figure 1.d). The RCAs were characterized through laboratory tests (Table 1).

\subsection{Natural aggregates}

Crushed quartzite and limestone were used as natural aggregates. The fine aggregate was limestone sand of $2 \mathrm{~mm}$ maximum particle size. The coarse aggregate was quartzite of $6 \mathrm{~mm}$ minimum size and $12 \mathrm{~mm}$ maximum size. The natural aggregates were characterized through laboratory tests (Table 1).

\subsection{Bitumen}

Modified bitumen type BM3c was chosen (Table 2 ). This bitumen can be used for many different traffic volumes and climates. 
Preliminary laboratory and field studies were performed on surface properties of pavement with recycled ceramic aggregates.

\subsection{Preliminary laboratory study}

The polishing resistance of RCA was evaluated through a preliminary laboratory study. Accelerated polish test (NLT-174) [19] was carried out on samples produced using characterized natural quartzite aggregates and RCA. Accelerated polishing coefficient (APC) variation regarding the amount of RCA and surface characteristics was studied on 6 tests.

The results showed that the addition of recycled ceramics decreased APC (Figure 2). APC resulted lower than the required by the Spanish specifications for medium traffic volumes (T1T31 Spanish traffic categories, APC $\geq 50 \%$ ). However, for low traffic volumes (T32-T4 Spanish traffic categories, $A P C \geq 44 \%$ ), the samples with a ceramic aggregate content of $15.5 \%, 31.1 \%$ and $55.5 \%$ had higher values to the required minimum, so were technically feasible for those traffic volumes.

The polishing resistance of wearing course was influenced by the presence of ceramic glazed faces on the surface. Empirical results indicated that an adjusted design of mixes with RCA could comply to the Spanish specifications.

The sample with $31.1 \%$ of RCA had an APC of $47 \%$, so it could be used as asphalt mixes of wearing courses with traffic levels from categories T1 to T4. However, a slight lack of APC was found for higher traffic volumes. An appropriate formulation of aggregates mix may supply it.

\subsection{Preliminary field study}

A preliminary field study was carried out to characterize the influence of RCAs addition on superficial features of a surface course.

147 An experimental section was executed in a low-volume rural road with an Annual Average Daily

148 Traffic (AADT) of approximately 600 vehicles per day during the field experiment. The section 149 was a two-lane road, with $3.15 \mathrm{~m}$ lane width, without shoulders and 1,200 m long (Figure 3). The HMA executed was a semi-dense asphalt concrete for surface course with $16 \mathrm{~mm}$ of maximum aggregate size and standard grade bitumen 35/50 (AC22 SURF 35/50 S type), with 
$4.70 \%$ of binder content. The amount of RCAs was different in each roadway direction, with $30 \%$ of RCAs in the lane A and $20 \%$ in the lane B.

After eleven months under traffic circulation, the wearing course was auscultated in each lane. Three control profiles, with three control points in each profile, were defined in each lane. The presence of glazed and ceramic faces on the surface was also studied.

The results (Table 3 ) showed good values of lateral friction coefficient (lane $A=77.55 \%$, lane $B$ $=68.23 \%)$, over the Spanish specifications $(65 \%)$. The average values of macrotexture (lane $\mathrm{A}$ $=0.66 \mathrm{~mm}$, lane $B=0.67 \mathrm{~mm}$ ) were slightly insufficient for the requirements of Spanish specifications $(0.70 \mathrm{~mm})$ (Figure 3).

\section{Methodology}

The designed methodology consisted of (Figure 4): characterization of natural and recycled ceramic aggregates (RCA) according to their aptitude to be used in HMA; design and characterization of the open graded wearing courses, with both natural aggregates and partial replacement of natural aggregates by recycling through laboratory tests; analysis of suitability and feasibility of using recycled ceramic aggregates in HMA surface course.

\subsection{Aggregate characterization}

The raw materials used in the study are shown in Table 4.

The filler was recovered from the aggregates processing plant during the production of both natural and recycled-with aggregates mix.

Natural and recycled aggregates were completely characterized through laboratory tests on cold mixed fraction samples (Table 1), according to Spanish and European specifications (UNEEN 13043:2003+AC:2004) [20]. The characterization tests included: sieve analysis; specific gravity of coarse, fine and filler aggregates; water absorption; sand equivalent; bulk density in toluene; flakiness index; and, Los Angeles abrasion value test.

The ceramic material was characterized by the presence of slabs. The slabs appearance was higher on porcelain material due to greater compactness. Besides, the RCAs were characterized by lower cleanliness and more natural moisture than natural aggregates. 
The RCAs had a lower specific gravity and bulk density compared to the natural aggregates, related to higher air void content. Higher air void content entails more porosity and asphalt binder absorption, as well as the existence of more fatigue points for fracture initiation and less cohesion on the mixture. RCA had lower toughness and abrasion resistance in respect to quartzite for similar particle size, as the L.A. abrasion value test showed. However, the RCA had adequate toughness and abrasion resistance for using in medium traffic volumes (below the L.A. abrasion value of $25 \%$ established at specifications).

\subsection{Experimental design of hot bituminous mixtures}

The selected mixture type was an open graded wearing course with maximum aggregate size of $11 \mathrm{~mm}$, with modified bitumen type BM3c (BBTM 11B Bm3c).

The design process was carried out according to Spanish specifications (PG-3). Main considered factors were: characteristics of aggregates, specially their typology and particle size; and, binder content.

The granulometric fit was carried out (Figure 5), according to particle size spindles specified in the Spanish standards.

To optimize the mixture binder content, an experimental laboratory study was carried out. The minimum dosage value set by the Spanish specifications was $4.75 \%$. The obtained working formula allowed the feasibility of execution and use of the mixture.

A conventional mixture $(\mathrm{CM})$ with natural quartzite and limestone aggregates was produced in laboratory conditions and completely characterized through laboratory tests.

Taking as baseline the $\mathrm{CM}$ working formula, the mixture with recycled ceramic aggregates (RCM) was designed. Preliminary and specific studies were carried out to develop the RCM working formula in respect to the percentages of ceramic and natural aggregates.

\subsubsection{Preliminary study}

The first approximation to the working formula was performed by several experimental tests under the variation of ceramic percentage and natural aggregates, as well as binder content. It was an iterative process with some feedback flows to meet required specifications. Ceramic aggregates were more porous than quartzite aggregates, involving higher bitumen absorption, specifically of the lighter phases of the bitumen under working temperatures. Therefore, higher 
amount of RCAs caused a lower cohesion of the RCM, also an increase of air void content and a plastic behavior. Besides, the previous results from the field and laboratory studies of aggregates were also considered for the mixture design. The amount of RCAs conditioned the superficial characteristics of wearing course, modifying the polishing resistance.

According to all the available data, the content of RCA was established on $30 \%$ of the total mass of aggregates for the studied mixtures (Table 5).

\section{$214 \quad$ 5.2.2. Specific study}

215 The specific study of the RCM consisted on the final design of the recycled ceramic mixture, 216 based on preliminary results and laboratory experimental tests. According to European 217 specifications, binder content was determined by the study of binder content points in both CM 218 and RCM. A set of three compacted specimens were produced for each binder content point 219 and mixture type to determine the reproducibility of the results. The optimum binder content was $2204.6 \%$ for $\mathrm{CM}$ and $5.0 \%$ for $\mathrm{RCM}$ with $30 \%$ of $\mathrm{RCA}$, agreeing specifications: filler/binder ratio = 1.2; ITSr $\geq 90 \%$; air particle loss $<15 \%$; wheel tracking deformation between 0.07 and $0.10 \mathrm{~cm}$; and, air void content $\geq 12 \%$. As an exception, ITSr was slightly below the specification value for RCM.

The mixtures were produced both in laboratory and in an asphalt plant, assessing the influence of real production factors. The complete mixture characterization was carried out according to the prescribed tests in the Spanish specifications, which includes the European Conformity marking (CE mark). These tests corresponded with: binder content (EN 12697-39:2006) [21]; bulk density (EN 12697-6:2012) [22]; air void content (EN 12697-8:2003) [23]; air particle loss (EN 12697-17: :2006+A1:2007) [24], also used as an indicator of cohesion; water sensitivity (EN 12697-12:2009) [25], determinated through the indirect tensile strength ratio (ITSr), obtained by the relation between the indirect tensile strength of water-dipped and air-dry specimens; and, resistance to permanent deformation with wheel tracking method (EN 12697-22:2008) [26], by measuring the rut depth formed by repeated passes of a loaded wheel. plant. In addition, these tests were completed with water particle loss test (Cantabrian test, NLT352) [27]. 


\section{Results}

238 The results obtained from the characterization tests for the CMs and the mixtures with recycled ceramic aggregates (RCM), with a ceramic percentage of $30 \%$ over the total mass of aggregates, are presented in Table 6.The results for the mixtures produced in laboratory and in asphalt plant were also studied, comparing the specification requirements.

Notable variations of the properties in respect to laboratory or asphalt plant processing were observed, despite having similar design parameters, such as binder content or filler/binder relation. Mixtures from asphalt plant presented higher air void content than mixtures produced at laboratory, particularly the CM.. Asphalt plant CM had a greater water particle loss (128.1\%) air particle loss $(75.9 \%)$ with respect to laboratory mixture.

Asphalt plant RCM presented a slight variation of binder content (2.2\%) and filler/binder relation $(-4.2 \%)$ respect to laboratory RCM. The air void content was similar for both mixtures, although water sensibility and particle loss varied, worth mentioning is asphalt plant RCM respect to laboratory. The water sensibility of asphalt plant RCM was significantly higher than the laboratory one, which presented lower resistance after immersion afor the indirect tensile strength ratio (ITSr) test (21.5\%). Water and air particle loss increased by $16.9 \%$ and $13.0 \%$ respectively in asphalt plant RCM with respect to laboratory RCM.

The binder content tended to increase slightly in asphalt plant production. Otherwise, filler/binder relation and bulk density tended to slightly decrease in asphalt plant mixtures.

The final asphalt plant mixtures were compared in order to evaluate the effects of partial substitution of natural aggregates by ceramic recycled aggregates (Table 6) in real conditions of production. RCM produced in asphalt plant with a $30 \%$ of RCA required a higher binder content and filler (10.4\%) and had lower bulk density (8.7\%) compared to CM, as shown in previous studies with ceramic aggregates due to less compactness and higher water absorption capability of ceramic material [4]. The air void content was greater in RCM than in the CM (20.0\%), with both cases having values above $12.0 \%$ corresponding to an open grade mixture. The addition of ceramic aggregates produced an increase of resistance to plastic deformation, resulting in $9.8 \%$ lower wheel tracking deformation at RCM, in contrast with higher rutting deformation related to sanitary ceramic waste aggregate [4]. The RCM presented slightly higher water sensibility than the $\mathrm{CM}(8.5 \%)$ after immersion at the indirect tensile strength ratio (ITSr) 
test, confirming previous sanitary-waste research [4], but refuting insulator-waste research findings [9]. Nonetheless, both mixtures were below Spanish specification values ( $\geq 90 \%)$. The RCM presented lower water particle loss than the $\mathrm{CM}(6.9 \%)$, although $\mathrm{RCM}$ air particle loss was higher (18.9\%).

271

272

\section{Discussion}

The research confirmed that the open graded wearing course designed with recycled ceramic aggregates presented enough mechanical and surface properties to consider this aggregate as a feasible raw material for HMA.

The addition of ceramic aggregates in the RCM conditioned a higher binder and filler contents, besides a lower bulk density compared to the $\mathrm{CM}$. This was a recurrent problem shown by several studies with other recycled aggregates lacking compactness, such as those obtained from construction and demolition wastes [7] or ceramic-industry wastes [4] [9]. The increase of recycled aggregates causes the hard descent of the mixture density and the increase of air void content. The higher air void content combined with greater water absorption capabilityspecifically observed with recycled ceramic aggregates from sanitary [4] or insulator industry wastes [9]—causes a larger binder absorption by aggregates during hot mixing. A bigger binder content offsets the binder absorption and maintains a suitable value of air void content.

The RCM presented poor behavior after water immersion, in both the indirect tensile strength resistance after immersion and the water particle loss test. The higher moisture sensibility is related with the lower specific gravity of RCAs_-involving more porosity in aggregates. Despite the higher binder content, greater binder absorption of RCA involves a lack of an effective asphalt covering the aggregates, encouraging the binder displacement by the water [7]. Besides, the RCA usually presents a glazed surface that disallowed entire asphalt-aggregate adherence [4], Those can lead to more fatigue points for fracture initiation defects and the stripping of aggregates, resulting in the loss of mechanical and superficial properties. Further, the increase of water sensibility appears to be related with the amount of RCA added, agreeing to previous studies that showed better moisture performance with low percentage of RCAbetween 20 to $40 \%$ of sanitary-waste aggregate added [4]— or even no significant influence of water in the RCM $-15 \%$ of insulator-waste aggregate added [9]. However, higher percentage 
of RCA is also related with higher water sensibility in the RCM-above $40 \%$ of sanitary-waste aggregate added resulted in a low indirect tensile strength resistance [4].

The RCAs were less resistant to abrasion with respect to quartzite aggregate for similar particle size. The lower polishing resistance and binder-aggregate adhesion on the RCM surface can influence the suitable durability and performance on surface.

Nonetheless, the addition of RCAs produced an increase of resistance to plastic deformation of mixture. A higher plastic deformation resistance involves less rutting deformation. This differs with the earlier study carried out with sanitary-waste aggregate in HMA, that shown the rise of permanent deformation with the recycled aggregate addition [4].

The air particle loss obtained by RCM showed good values, despite of the lack of adhesion related to the presence of glazed surfaces and higher binder absorption by aggregates. Nonetheless, previous studies with insulator-waste aggregates indicated the presence of several smooth pieces of ceramic aggregate at the end of some tests [9].

The RCA presented suitable properties to Utilizing in HMA with respect to other wasteaggregates [4] [7] [9], despite some limiting features. Mainly, the lower specific gravity and the greater water absorption capability of the RCA increase the water sensibility and can encourage performance problems in the mixture.

With the production methodology, the mixtures produced in an asphalt plant basis presented higher void content than the mixtures produced in a laboratory. This fact shows mismatches on the production process, in consistence with previous studies that established higher void contents of plant-mixed material compared to laboratory-mixed material [28].

317 Therefore, the open graded wearing course with recycled ceramic aggregates is considered

318 feasible for medium-low volume roads, although further research is needed to ensure technical 319 and economical viability.

\section{Conclusions and further recommendations}

321 Based on the results of the research and regarding materials themselves the following conclusions can be drawn: compared to the quartzite aggregates. 
- The RCAs are less resistant to abrasion in respect to quartzite for similar particle size. Besides, presence of glazed faces influenced asphalt-aggregate adhesion and polishing resistance.

- Empirical results indicate that an adjusted design of mixes with $30 \%$ RCA in partial substitution of natural aggregates can meet most of the required Spanish specifications.

For the recycled ceramic aggregate-with mixture BBTM 11B, the main conclusions extracted are: required bitumen and the air void content.

- The RCM presents better resistance to plastic deformation, although water sensitivity and particle loss properties are worse compared to $\mathrm{CM}$. The most limiting factor for RCM is the indirect tensile strength ratio (ITSr), as a performance indicator for water sensitivity, since the values are below Spanish specifications.

Therefore, recycled ceramic wastes are considered technically feasible to be incorporated as aggregates into asphalt concrete mixtures for open graded wearing courses. The mixture with $30 \%$ of recycled ceramic aggregates by aggregates weight meet most of the mechanical and superficial characteristics established within Spanish specifications to be used as road surface layer for medium-low traffic volumes, with exception of water sensibility which should be improved by adjusting the working formula. The methodology validation will depend on the results of experimental sections under real traffic conditions.

Future research can evaluate other mixtures types with RCA content in respect to their should be carried out to determine repeated and static creep, or fatigue and stiffness modulus. In addition, comprehensive analysis of $10 \%, 20 \%, 30 \%, 40 \%, 50 \%$ and $60 \%$ replacements of natural aggregate by RCA and experimental evaluation should be carried out to determine the optimal replacement amount in the future. Finally, the exclusive use of porcelain tile wastewhich is more dense and compact than stoneware-should be analyzed, as a better mixture performance is expected. 


\section{Acknowledgements}

355 This research would not have been possible without the support of the Research and

356 Development Program of the Institute for Small and Medium Industry from Valencia (IMPIVA, №

357 Exp. IMIDTF/2011/56), financed by the European Union under the Operational Program of the 358 European Regional Development Fund (ERDF).

359 
361 [1] Lee JM, Salgado R, Benal A, Novell CW. Shredded tires and rubber-sand as lightweight backfill. J Geotech Geoenviron 1999; 25, 2: 132-141.

363 [2] Higashiyama H, Sappakittipakorn M, Sano M, Yagishita, F. Chloride ion penetration into mortar containing ceramic waste aggregate. Constr Build Mater 2012; 33: 48-54.

[3] Poon CS, Chan D. Feasible use of recycled concrete aggregates and crushed clay brick as unbound road sub-base. Constr Build Mater 2006; 20: 578-585. Ceramic Aggregates in Wearing Layer of Asphalt Pavement. J Mater Civil Eng 2013; posted ahead of print.

[5] Federal Highway Administration (FHWA). User guidelines for waste and by product materials in pavement construction. FHWA-RD-97-148; 1997. [6] Hassan KE, Elghali L, Sowerby C. Development of new materials for secondary and recycled aggregates in highway infrastructure. Transport Research Laboratory (TRL); Unpublished Project Report PR CPS/30/03; 2004. [7] Pérez I, Pasadín AR, Medina L. Hot mix asphalt C\&D waste as coarse aggregates. Mater Design 2012; 36: 840-846.

[8] Zohrabi M, Karami S. Applicability of Alternative Aggregates in Asphalt Pavements and

378 Their Performance Requirements. Coventry University and The University of Wisconsin Milwaukee. Second international conference on Sustainable Construction Materials and Technologies Proceedings 2010.

[9] Van de Ven MFC, Molenaar AAA,Poot MR. Asphalt mixtures with waste materials: possibilities and constraints. 10th Conference on Asphalt Pavements for Southern Africa Proceedings 2011.

384 [10] Spanish Ministry of Public Works. Pliego de Prescripciones Técnicas Generales para obras de carreteras y puentes de la Dirección General de Carreteras (PG-3). Ministerio de Fomento, Dirección General de Carreteras 2008.

387 [11] Koyuncu H, Guney Y, Yilmaz G, Koyuncu S, Bakis R. Utilization of Ceramic Wastes in the 388 Construction Sector. Key Engineering Materials 2004; 264-268: 2509-2512.

389 [12] Huang B, Dong Q, Burdette EG. Laboratory evaluation of incorporating waste ceramic 390 materials into Portland cement and asphaltic concrete. Constr Build Mater 2009; 23: 3451-3456. 
[13] Pacheco-Torgal F, Jalali S. Reusing ceramic wastes in concrete. Constr Build Mater 2010; 24: $832-838$.

393 [14] Muniandy R, Aburkaba E, Mahdi L. Effects of mineral filler particle size and type on permanent deformation of stone mastic asphalt mixtures. G. J. P\&A Sc and Tech. 2012; 2012v02i2: 50-64.

396 [15] Gahlot V. Ceramic Waste as a pavement construction material. Govt. Polytechnic College, 397 Bikaner, Rajasthan (India). Unpublished Results; 2011. Available from:

398 http://es.scribd.com/doc/61852837/Ceramic-Waste-1, accessed December 2012)

399 [16] Krüger G, Solas H. Einsatz von Sanitärkeramikrezyklat. Aufhellungsmaterial für 400 Asphaltdeckschichten. BR Baustoff Recycling + Deponietechnik 2008; 24: 30-38.

401 [17] NLT-159/00. Marshall Method for hot mix aspahtl. Spanish Centre for studies and experimentation on public works (CEDEX); 2000.

403 [18] UNE-EN 12697. Spanish (European) Standards. Bituminous mixtures. Test methods for 404 hot mix asphalt. Spanish Association for Standardization and Certification (AENOR); 2012.

405 [19] NLT-174/72. Accelerated polishing of aggregates. Spanish Centre for studies and 406 experimentation on public works (CEDEX); 1972.

407 [20] UNE-EN 13043:2003+AC:2004. Aggregates for bituminous mixtures and surface 408 treatments for roads, airfields and other trafficked areas. Spanish Association for 409 Standardization and Certification (AENOR); 2004.

410 [21] UNE-EN 12697-39:2006. Bituminous mixtures. Test methods for hot mix asphalt. Part 39:

411 Binder content by ignition. Spanish Association for Standardization and Certification (AENOR); 4122006.

413 [22] UNE-EN 12697-6:2012. Bituminous mixtures. Test methods for hot mix asphalt. Part 6:

414 Determination of bulk density of bituminous specimens. Spanish Association for Standardization 415 and Certification (AENOR); 2012.

416 [23] UNE-EN 12697-8:2003. Bituminous mixtures. Test methods for hot mix asphalt. Part 8:

417 Determination of void characteristics of bituminous specimens. Spanish Association for 418 Standardization and Certification (AENOR); 2003.

419 [24] UNE-EN 12697-17:2006+A1:2007. Bituminous mixtures. Test methods for hot mix asphalt. 420 Part 17: Particle loss of porous asphalt specimen. Spanish Association for Standardization and 421 Certification (AENOR); 2007. 
422 [25] UNE-EN 12697-12:2009. Bituminous mixtures. Test methods for hot mix asphalt. Part 12:

423 Determination of the water sensitivity of bituminous specimens. Spanish Association for

424 Standardisation and Certification (AENOR); 2009.

425 [26] UNE-EN 12697-22:2008+A1:2008. Bituminous mixtures. Test methods for hot mix asphalt.

426 Part 22: Wheel tracking. Spanish Association for Standardization and Certification (AENOR);

4272008.

428 [27] NLT-352. Cantabrian test of abrasion loss. Spanish Centre for studies and experimentation 429 on public works (CEDEX); 1986.

430 [28] Von Quintus H, Scherocman J, Hughes C. Asphalt-Aggregate Mixtures Analysis System:

431 Philosophy of the Concept. Asphalt Concrete Mix Design Development of More Rational

432 Approaches. ASTM STP 1041, W. Gartner, Jr., Ed. American Society for testing and Materials, 433 Philadelphia; 1989: 15-38.

434 


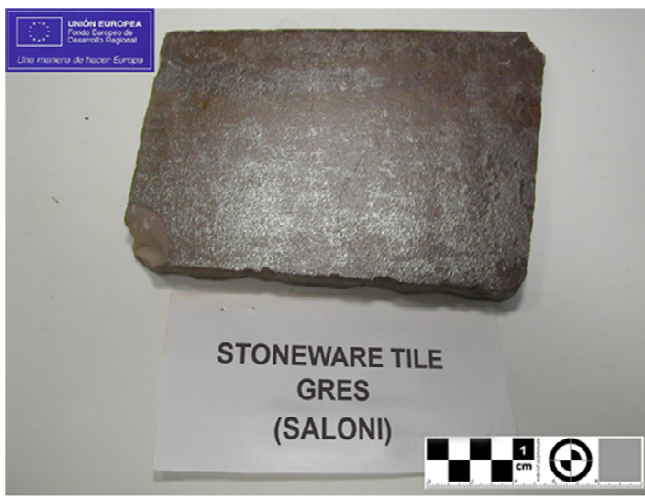

(a)

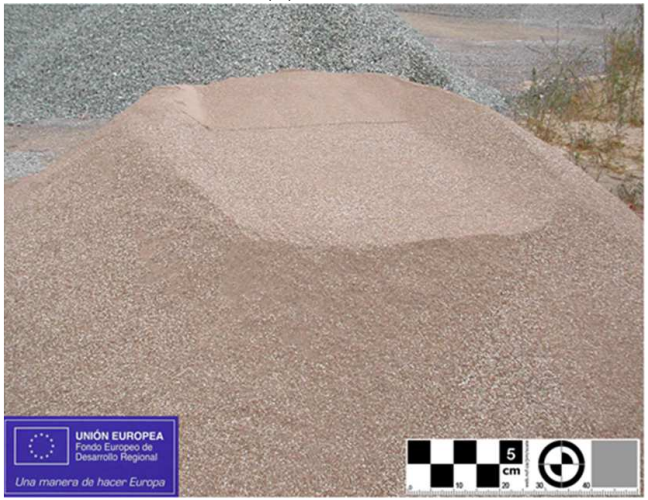

(c)

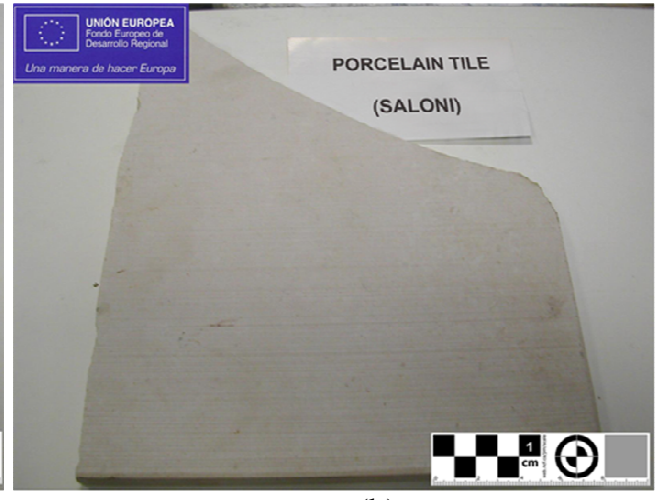

(b)

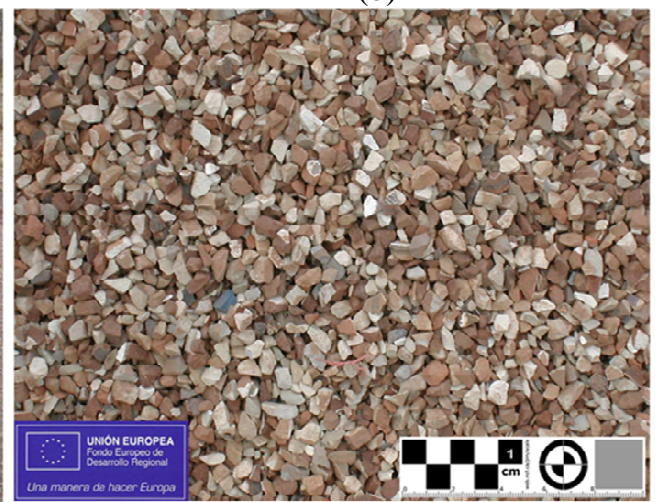

(d)

Figure 1 (a) Stoneware tile waste; (b) Porcelain tile waste; (c) Recycled ceramic aggregates, 0-4 mm fine fraction; (d) Recycled ceramic aggregates, $4-11 \mathrm{~mm}$ coarse fraction

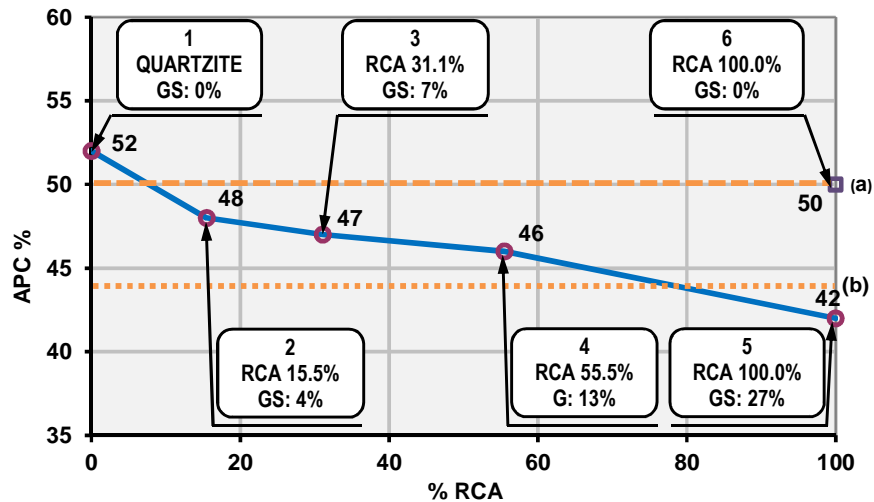

Note: GS = sample glazed surface percentage; (a) $\geq 50 \%$, T1-T31 traffic volumes, Spanish specifications; (b) $\geq 44 \%$, T32-T4 traffic volumes, Spanish specifications

Figure 2 Variation of polishing resistance through accelerated polish test 


\begin{tabular}{|c|c|c|c|c|c|}
\hline \multicolumn{3}{|c|}{$3.15 \mathrm{~m}$} & \multicolumn{3}{|c|}{$3.15 \mathrm{~m}$} \\
\hline \multicolumn{3}{|c|}{ AC22 SURF $35 / 50 \mathrm{~S}(20 \% \mathrm{RCA})$} & \multicolumn{3}{|c|}{ AC22 SURF $35 / 50 \mathrm{~S}(30 \% \mathrm{RCA})$} \\
\hline $\begin{array}{c}0.70 \mathrm{~m} \\
\mathrm{~B}_{1} \\
\end{array}$ & $\begin{array}{c}1.59 \mathrm{~m} \\
\mathrm{~B}_{2} \\
\end{array}$ & $\begin{array}{c}2.44 \mathrm{~m} \\
\mathrm{~B}_{3}\end{array}$ & $\begin{array}{c}\mid \\
0.70 \mathrm{~m} \\
\mathrm{~A}_{3}\end{array}$ & $\begin{array}{c}1.59 \mathrm{~m} \\
\mathrm{~A}_{2} \\
1\end{array}$ & $\begin{array}{c}2.44 m \\
A_{1} \\
\end{array}$ \\
\hline $\begin{array}{c}\text { EXTERNAL } \\
\text { TRACK }\end{array}$ & $\begin{array}{l}\text { CENTER } \\
\text { TRACK }\end{array}$ & $\begin{array}{l}\text { INTERNAL } \\
\text { TRACK }\end{array}$ & $\begin{array}{l}\text { INTERNAL } \\
\text { TRACK }\end{array}$ & $\begin{array}{c}\text { CENTER } \\
\text { TRACK }\end{array}$ & $\begin{array}{c}\text { EXTERNAL } \\
\text { TRACK }\end{array}$ \\
\hline
\end{tabular}

\section{HOT MIX BITUMINOUS DESIGN}

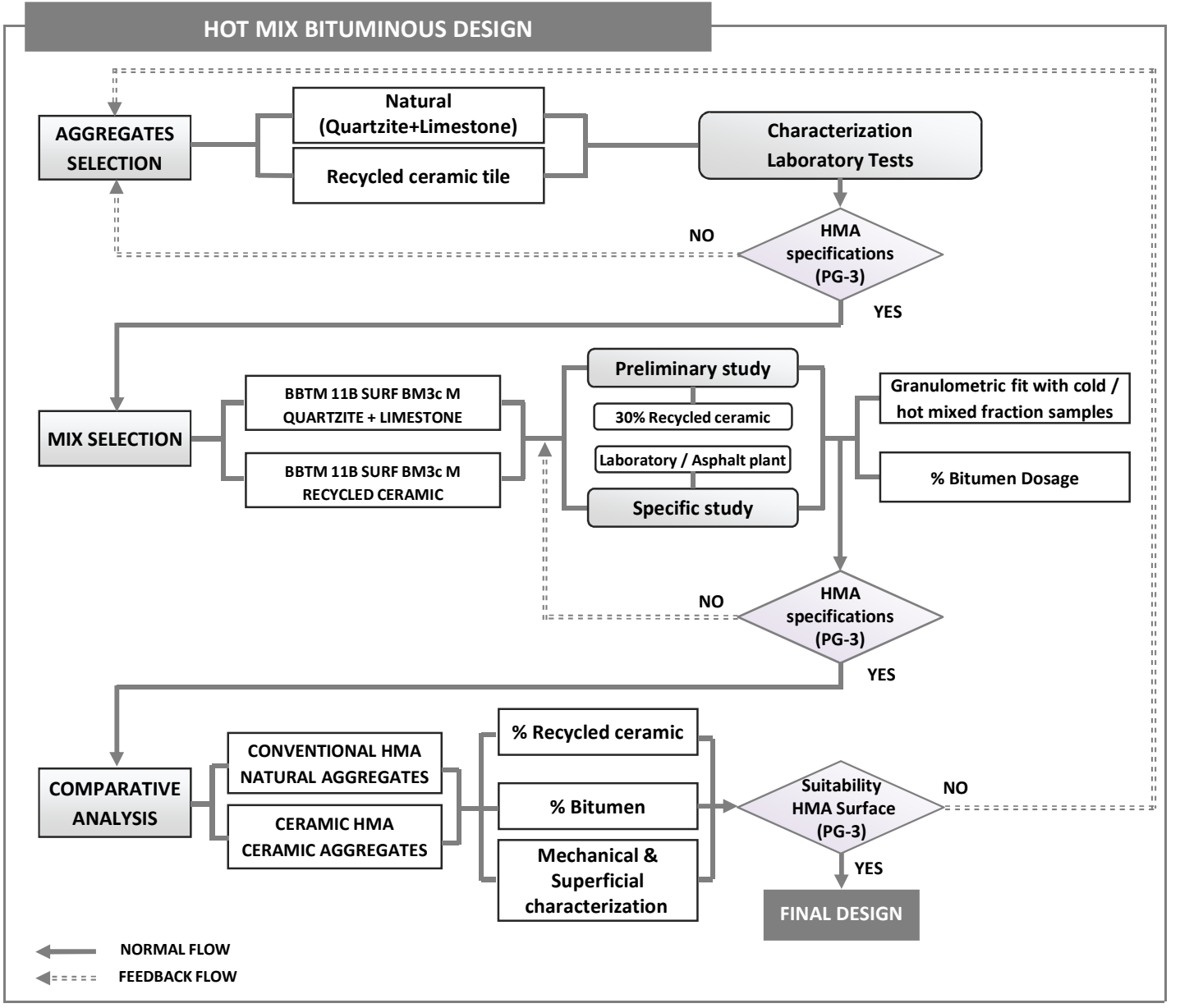




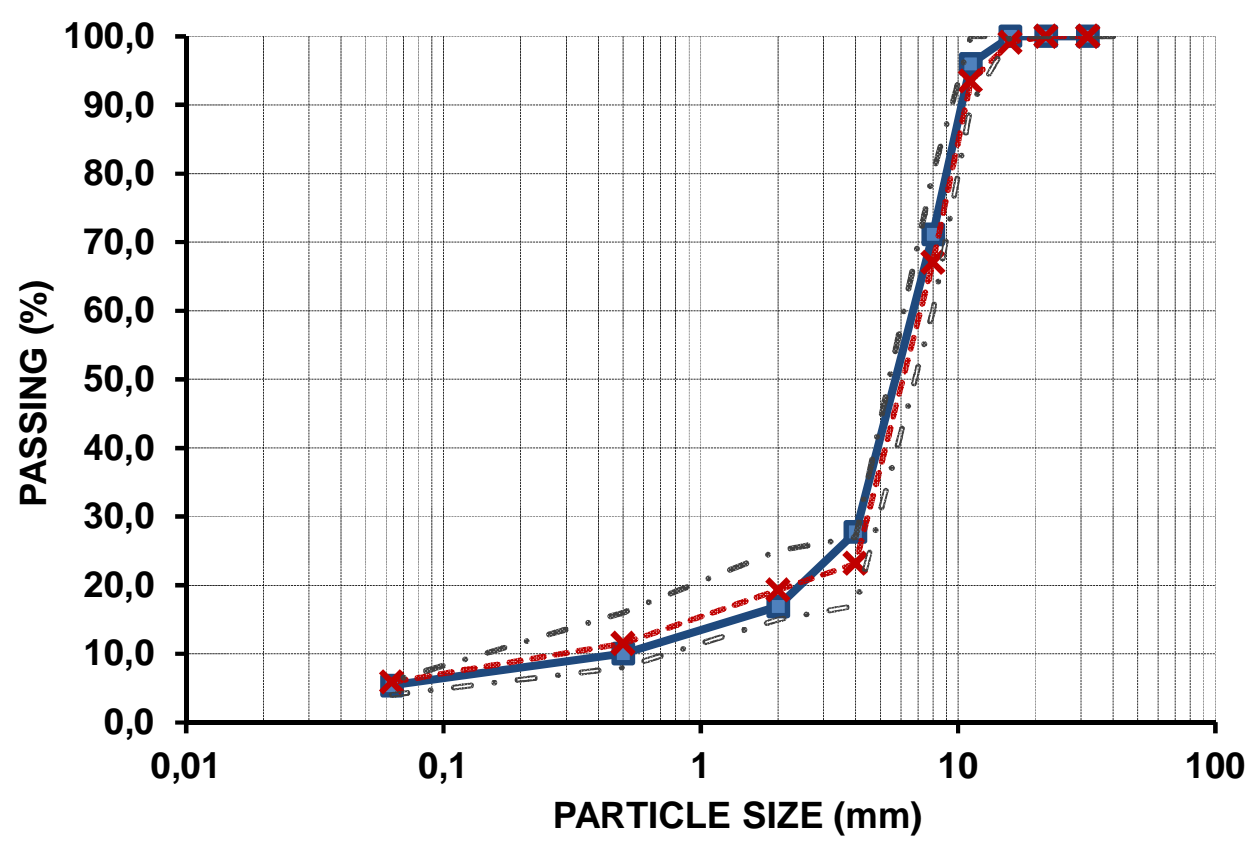

457 - CONVENTIONAL

$-*-30 \%$ RCA

458

- - Upper values

$\odot$ - Lower values

459

Figure 5 Particle size distribution

460 


\begin{tabular}{|c|c|c|c|c|c|c|c|c|c|c|c|c|c|}
\hline SAMPLE & $\begin{array}{c}\mathbf{C} \\
(\%)\end{array}$ & $\begin{array}{c}\text { MIN } \\
(\mathbf{m m})\end{array}$ & $\begin{array}{c}\text { MAX } \\
(\mathbf{m m})\end{array}$ & $\begin{array}{c}\text { NM } \\
(\%)\end{array}$ & $\begin{array}{c}\text { OD } \\
\left(\mathbf{g} / \mathbf{c m}^{3}\right)\end{array}$ & $\begin{array}{c}\text { SSD } \\
\left(\mathbf{g} / \mathbf{c m}^{3}\right)\end{array}$ & $\begin{array}{c}\text { SG } \\
\left(\mathbf{g} / \mathbf{c m}^{3}\right)\end{array}$ & $\begin{array}{c}\text { WA } \\
(\%)\end{array}$ & $\begin{array}{c}\text { FILL } \\
(\%)\end{array}$ & $\begin{array}{c}\mathbf{S D} \\
\left(\mathbf{g} / \mathbf{c m}^{3}\right)\end{array}$ & $\begin{array}{c}\mathbf{F I} \\
(\%)\end{array}$ & $\begin{array}{c}\text { LA } \\
(\%)\end{array}$ \\
\hline $\begin{array}{c}\text { CERAMIC } \\
\text { SAND 0/4 }\end{array}$ & - & 0 & 4 & $2.34 \%$ & 1.890 & 2.157 & 2.577 & 14.10 & $9.00 \%$ & $\begin{array}{c}\text { EA- } \\
78\end{array}$ & 0.769 & - & - \\
\hline $\begin{array}{c}\text { CERAMIC } \\
\text { COARSE 4/11 }\end{array}$ & 1.14 & 4 & 11 & $1.27 \%$ & 2.212 & 2.300 & 2.425 & 3.96 & $1.10 \%$ & - & - & $9.0 \%$ & $21 \%$ \\
\hline $\begin{array}{c}\text { LIMESTONE } \\
\text { SAND 0/2 }\end{array}$ & - & 0 & 2 & $0.16 \%$ & 2.596 & 2.666 & 2.793 & 2.73 & $20.30 \%$ & $\begin{array}{c}\text { EA- } \\
60\end{array}$ & 0.714 & - & - \\
\hline $\begin{array}{c}\text { QUARTZITE } \\
\text { COARSE 6/12 }\end{array}$ & 0.72 & 6 & 12 & $0.58 \%$ & 2.698 & 2.718 & 2.762 & 0.93 & $0.72 \%$ & - & - & $12.6 \%$ & $13 \%$ \\
\hline
\end{tabular}

Note: $\mathrm{C}=$ cleanliness $(\% \# 0,063 \mathrm{~mm}) ; \mathrm{MIN}=$ minimum size; $\mathrm{MAX}=$ maximum size; $\mathrm{NM}=$ natural moisture; $\mathrm{OD}$ = oven-dry density; $\mathrm{SSD}$ = saturated surface-dry density; $\mathrm{SG}=$ specific gravity; $\mathrm{WA}=$ water absorption; FILL = filler $\leq 0,063 \mathrm{~mm} ; \mathrm{SE}=$ sand equivalent; $\mathrm{BD}=$ bulk density in toluene; $\mathrm{FI}=$ flakiness index; $\mathrm{LA}=\mathrm{Los}$ Angeles abrassion value; - = Data not aplicable.

\begin{tabular}{|c|c|c|c|}
\hline CHARACTERISTIC & METHOD & RESULT & UNIT \\
\hline \multirow{2}{*}{ Penetration $\left(25^{\circ} \mathrm{C} ; 100 \mathrm{~g} ; 5 \mathrm{~s}\right)$} & NLT-124 & 59 & $0.1 \mathrm{~mm}$ \\
\hline & UNE-EN I1426 & 59 & $0.1 \mathrm{~mm}$ \\
\hline Density $\left(25^{\circ} \mathrm{C} / 25^{\circ} \mathrm{C}\right)$ & NLT-122 & 1 & - \\
\hline Ductility $\left(5 \mathrm{~cm} / \mathrm{min}\right.$.) a $5^{\circ} \mathrm{C}$ & NLT-126 & 30 & $\mathrm{~cm}$ \\
\hline Viscosity (Float test $60^{\circ} \mathrm{C}$ ) & NLT-183 & 2000 & $\mathrm{~s}$ \\
\hline \multirow{2}{*}{ Softening point } & NLT-125 & 69 & ${ }^{\circ} \mathrm{C}$ \\
\hline & UNE-EN 1427 & 68 & ${ }^{\circ} \mathrm{C}$ \\
\hline Fraass breaking point & NLT-182 & -17 & ${ }^{\circ} \mathrm{C}$ \\
\hline Elastic recuperation $\left(25^{\circ} \mathrm{C}\right)$ & NLT-329 & 82 & $\%$ \\
\hline Flash point & NLT-127 & 235 & ${ }^{\circ} \mathrm{C}$ \\
\hline
\end{tabular}


468

469

470

471

\begin{tabular}{|c|c|c|c|}
\hline TYPOLOGY & SAMPLE & $\begin{array}{l}\text { PARTICLE } \\
\text { SIZE }\end{array}$ & SOURCE \\
\hline LIMESTONE AGGREGATES & LIMESTONE SAND 0/2 & $0 / 2 \mathrm{~mm}$ & $\begin{array}{c}\text { QUARRY “LA } \\
\text { TORRETA” (CASTELLÓN) }\end{array}$ \\
\hline QUARTZITE AGGREGATES & QUARTZITE 6/12 & $6 / 12 \mathrm{~mm}$ & $\begin{array}{l}\text { QUARRY RIUDECOLS } \\
\text { (TARRAGONA) }\end{array}$ \\
\hline \multirow{2}{*}{$\begin{array}{l}\text { RECYCLED CERAMIC } \\
\text { AGGREGATES }\end{array}$} & $\begin{array}{l}\text { RECYCLED CERAMIC SAND } \\
0 / 4\end{array}$ & $0 / 4 \mathrm{~mm}$ & \multirow{2}{*}{$\begin{array}{l}\text { LANDFILL "LA TORRETA" } \\
\text { "SALONI" CERAMIC } \\
\text { (CASTELLÓN) }\end{array}$} \\
\hline & $\begin{array}{c}\text { RECYCLED CERAMIC } \\
\text { COARSE } 4 / 11\end{array}$ & $4 / 11 \mathrm{~mm}$ & \\
\hline
\end{tabular}

Table 4 Basic typology and source of the used raw materials

473

Note: GF = Glazed faces; $S R=$ Average skid resistance; $\sigma S R=$ Standard deviation of the skid resistance; $M=$ Average macrotexture; $\sigma \mathrm{M}=$ Standard deviation of the macrotexture.

Table 3 Results from surface course auscultation 


\begin{tabular}{|c|c|c|c|c|c|c|c|c|c|}
\hline \multicolumn{2}{|c|}{ BBTM 11B BM3C } & BIN (\%) & F/B & $\mathrm{BD}\left(\mathrm{g} / \mathrm{cm}^{3}\right)$ & VOID (\%) & WTS $\left(\mathrm{mm} / 10^{3}\right)$ & ITSr (\%) & WPL (a) & APL \\
\hline \multirow{3}{*}{$\sum_{U}$} & Laboratory & 4.60 & 1.20 & 2.16 & 15.6 & - & \begin{tabular}{|l|}
91.7 \\
\end{tabular} & 11.4 & 5.4 \\
\hline & Asphalt plant & 4.63 & 1.18 & 2.06 & 20.6 & 0.041 & 73.2 & 26.0 & 9.5 \\
\hline & $\Delta$ Plant $_{\text {Lab }}(\%)^{(c)}$ & $0.7 \%$ & $-1.7 \%$ & $-4.6 \%$ & $31.9 \%$ & - & $-20.2 \%$ & $128.1 \%$ & $75.9 \%$ \\
\hline \multirow{3}{*}{$\sum_{0}$ i̊ } & Laboratory & 5.00 & 1.20 & 1.89 & 23.4 & - & 85.4 & 20.7 & 10.0 \\
\hline & Asphalt plant & 5.11 & 1.15 & 1.88 & 24.7 & 0.037 & 67.0 & 24.2 & 11.3 \\
\hline & $\Delta$ Plant $_{\text {Lab }}(\%)^{(c)}$ & $2.2 \%$ & $-4.2 \%$ & $-0.5 \%$ & $5.6 \%$ & - & $-21.5 \%$ & $16.9 \%$ & $13.0 \%$ \\
\hline \multicolumn{2}{|c|}{$\Delta \mathrm{RCM}_{\mathrm{CM}}{ }^{(d)}$} & $10.4 \%$ & $-2.5 \%$ & $-8.7 \%$ & $20.0 \%$ & $-9.8 \%$ & $-8.5 \%$ & $-6.9 \%$ & $18.9 \%$ \\
\hline \multicolumn{2}{|c|}{$\begin{array}{c}\text { SPECIFICATIONS } \\
\text { (PG-3) }\end{array}$} & $\geq 4,75$ & $\begin{array}{c}1,00- \\
1,20\end{array}$ & - & $\geq 12,0$ & $\leq 0.07$ & $\geq 90 \%$ & $\leq 25,0^{(b)}$ & $\leq 15,0$ \\
\hline
\end{tabular}

Note: BIN = binder content (EN 12697-39); F/B = filler/binder ratio; BD = bulk density (EN 12697-6); VOID = air void content (EN 12697-8); WTS = wheel tracking slope (mm/103 load cycles) (EN 12697-22); ITSr = water sensitivity ITSr (EN 12697-12); WPL = water particle loss test (NLT-352); APL = air particle loss (EN 12697-17); - = Data not applicable.

Footnote: (a) Complementary tests; (b) Not prescriptive in Spanish regulation; (c) $\Delta$ Plant Lab = Variation in asphalt plant mixture properties regarding laboratory mixture; (d) $\triangle \mathrm{RCMCM}=$ Variation in recycled ceramic mixture properties regarding conventional mixture, both from asphalt plant.

Table 6 Characterization of conventional and recycled-with mixtures produced in both laboratory and asphalt plant 